\title{
Cost of Medications, Preference and Willingness-to-Pay for Pain Relief among Adult Patients Diagnosed with Acute and Chronic Musculoskeletal Pain Conditions
}

\author{
AM Karoline V. Gabuyo and Shiela Marie S. Lavina
}

Department of Family and Community Medicine, College of Medicine and Philippine General Hospital, University of the Philippines Manila

\begin{abstract}
Objective. To determine the current cost, medication preferences, willingness to pay for symptom relief and reduced adverse events of adult patients with acute and chronic musculoskeletal pain.

Methods. This was a cross-sectional study among adult Filipinos consulted for musculoskeletal conditions at Family Medicine Clinic. Data were collected through a questionnaire and a systematic sampling of respondents.

Results. The study had a total of 342 participants with degenerative osteoarthritis as the most common primary diagnosis. Twenty percent ( $N=69 / 342$ ) were acutely symptomatic while $273 / 342(80 \%)$ have chronic musculoskeletal pain. Most would prefer medicines at a lower price point, effectively reduces pain, fast onset of action, longer therapeutic effects and less adverse effects. Willingness-to-pay was at an average price of Php 86.11 (SD \pm 15.47$)$ per pill for complete symptom relief.
\end{abstract}

Conclusion. Adult Filipinos with musculoskeletal pain symptoms prefer pain medicines with good symptom control, less adverse event and were willing to pay for complete symptom relief at an average of eighty-six pesos per pill.

Key Words: willingness to pay, cost of medication, pain relief, musculoskeletal pain

\section{INTRODUCTION}

Paper presented at the WONCA Asia Pacific Regional Conference, May 17, 2019, Kyoto, Japan.

Corresponding author: AM Karoline V. Gabuyo, MD, MPM-HSD Department of Family and Community Medicine Philippine General Hospital University of the Philippines Manila

Taft Avenue, Ermita, Manila 1000, Philippines

Email:avgabuyo@up.edu.ph
Musculoskeletal pain symptoms affecting daily activities and functional capacity are common reasons for clinic consultations in Family Medicine practice. It is estimated that in the Asia-Pacific Region, around 12- 45\% of the population is afflicted with musculoskeletal problems. ${ }^{1} \mathrm{~A}$ similar estimate of $10.4 \%$ in the Filipino populace was reported with an annual incidence of $3.4 \%$ accounted for mostly by a diagnosis of osteoarthritis. ${ }^{2}$ Likewise, $8-10 \%$ of out-patient consultations at the Family Medicine OutPatient Clinic of Philippine General Hospital are due to musculoskeletal conditions.

Acute and chronic musculoskeletal pain causes physical impairment and functional limitations that affect a person's psychosocial and quality of life. ${ }^{3}$ It is considered to be an important illness of society because of its association with a high health economic burden involving the loss of functional capacity of people to work and the increased cost of the prevention and treatment. The burden caused by musculoskeletal pain on both functional and quality of life necessitates immediate symptom relief provided by analgesic 
medications. Effectiveness of therapy, however, differ across types of pain medications, nature, and severity of pain.

With the increasing cost of therapeutic management, an economic evaluation of medicines for use in musculoskeletal pain conditions is important and should be taken into account by health care providers. ${ }^{4}$ Willingness-to-pay is a measure of benefit that can give a monetary value to a type of medication being used. The maximum amount of money a patient is willing to pay is therefore indicative of the value a patient gives for its health benefits. ${ }^{5}$ Specific characteristics of medicine such as efficacy, safety, and ease of use can influence an individual's willingness-to-pay for drugs. ${ }^{6}$ Furthermore, function and sense of well-being also show a significant effect on willingness-to-pay because patients who are less depressed and with relatively low anxiety states have shown higher willingness-to-pay qualities. ${ }^{4}$

The provision of monetary value to health improvement allows a critical comparison between the costs of therapeutic interventions and the total benefits the interventions will give patients. By understanding what Filipino patients will be willing to pay for the improvement of pain symptoms related to musculoskeletal diseases, health care providers can recognize the relative value of pain and functional improvement among patients and thereby can provide a more effective pain management strategy given a poorresource condition. Likewise, an overview of the pain-related out-of-pocket expenditures of patients for musculoskeletal conditions can assist in the decision-making process in providing a cost-efficient and beneficial medicine for chronic pain related diseases in the primary care setting.

The objective of this study was to determine the current cost, patient medication preferences and willingness to pay for complete symptom relief, reduced adverse events and improved sense of well-being among adult patients consulting for acute and chronic musculoskeletal pain at Family Medicine Clinic of UP-PGH.

\section{METHODS}

This was a cross-sectional study involving adult Filipino patients with acute and chronic musculoskeletal pain symptoms and diagnosed with myofascial pain syndrome, arthritic pain, and chronic low back pain, who use oral and/or topical analgesics for symptom relief at Family Medicine Clinic of UP-PGH.

The study exclusion criteria include the following conditions: pain condition directly caused by trauma within the last three months, musculoskeletal pain resulting from or associated with malignancy and chronic autoimmune diseases that warrant other method of analgesic delivery aside from oral and topical, presence of unstable comorbidities, body mass index of greater than $40 \mathrm{~kg} / \mathrm{m}^{2}$, patients taking more than 10 tablets/capsules of medicines per day, use of oral combination analgesics, and use of benzodiazepines.
Data were gathered through an interviewer-administered questionnaire among respondents selected via systematic sampling. The data collection tool was developed using a review of recent literature to identify the effectiveness data and characteristic attributes of medications that were important to patients. The literature search was conducted using PubMed database, Herdin, and Google Scholar, with a review of all relevant articles in English published between 1998 to 2016. The key concepts identified in the literature search were utilized for question statements and to confirm treatment preferences and ideas.

The questionnaire was composed of mixed closed and open-ended questions, pictures, and diagrams based on study objectives. Tasks questions were included to check for respondents' comprehension and understanding of the items and therefore served as consistency checks to ensure that study participants correctly understood the questions.

The main outcomes measured were the average cost of medicine expressed in Philippine peso that patients were willing to pay for complete symptom relief, $90 \%, 50 \%$ or $30 \%$ effective in providing pain relief. This study also measured the average cost of medicine patients were willing to pay on a drug that provides 50\% less adverse effect and 90\% less adverse effect. Patient's preference in choosing medicines for musculoskeletal pain was also determined thru questions involving clinical scenarios. Moreover, respondents' sense of well-being was evaluated through WHO Well-being Index.

All data were encoded in MS Excel version 2016 and statistical analyses were done using an evaluation copy of IBM SPSS Statistics v. 23.0. All categorical data such as sex, educational attainment was summarized using frequency, proportions while numerical data such as age were summarized using mean, median and standard deviation. Crosstabulations were done for sociodemographic, clinical, medication preference variables and pain classification (acute and chronic).

Ethics approval was obtained before the conduct of the study from UP Manila Research Ethics Board [UPMREB (FMC)-2016-211-01].

\section{RESULTS}

\section{Sociodemographic and Clinical Characteristics}

A total of 342 adults with musculoskeletal pain were included in the study.

Twenty percent $(\mathrm{N}=69)$ were acutely symptomatic (pain < 6months) while $273(80 \%)$ have musculoskeletal pain of greater than 6 months (chronic pain). The majority of the respondents $(86 \%)$ were gainfully employed with an average monthly household income of Php 9,558.65 (SD \pm 6037.59).

Degenerative osteoarthritis was the primary diagnosis in $41 \%$ and $78 \%$ of respondents with acute and chronic pain, respectively. Adults with chronic symptoms were 10 years older compared to respondents presenting with acute pain symptoms (Table 1). All participants were seen and treated 
Table 1. Socio-Demographic and Clinical characteristics of Adult Filipinos with Acute and Chronic musculoskeletal pain seen and managed at the Family Medicine Clinic of Outpatient Department of Philippine General Hospital, September 2016 - April 2017

\begin{tabular}{|c|c|c|}
\hline Variables & Chronic Musculoskeletal Pain ( $\mathrm{N}=273$ ) & Acute Musculoskeletal Pain ( $\mathrm{N}=69)$ \\
\hline Age, $X(S D)$, years & $61(\mathrm{SD} \pm 9.04)$ & $51(S D \pm 11.89)$ \\
\hline \multicolumn{3}{|l|}{ Sex, \% } \\
\hline Male/Female & $24 \%(65) / 76 \%(208)$ & $30 \%$ (21) / 70\% (48) \\
\hline Body Mass Index, X(SD) & $23.76(S D \pm 3.25)$ & $23.93(\mathrm{SD} \pm 3.68)$ \\
\hline \multicolumn{3}{|l|}{ Educational attainment, \% } \\
\hline Elementary graduate & $13 \%(37)$ & $7 \%(5)$ \\
\hline Secondary graduate & $55 \%(149)$ & $44 \%(30)$ \\
\hline College graduate & $32 \%(87)$ & $49 \%(34)$ \\
\hline Gainful Employment, \% & $87 \%(236)$ & $83 \%(57)$ \\
\hline Estimated Household monthly income, X (SD), Pesos & Php9,016.54 (SD \pm 5844.76$)$ & Php11,695.65 (SD \pm 6349.05$)$ \\
\hline Duration of pain symptoms in months, $X(S D)$ & $15.08(\mathrm{SD} \pm 15.08)$ & $4.19(\mathrm{SD} \pm 1.68)$ \\
\hline Length in months since started pain medication, $X(S D)$ & $20.11(S D \pm 14.60)$ & $4.09(\mathrm{SD} \pm 1.71)$ \\
\hline Current level of pain (VAS), X (SD) & $8.32(\mathrm{SD} \pm 1.25)$ & $8.10(\mathrm{SD} \pm 1.29)$ \\
\hline Cost of current pain medication per pill, $X(S D)$, pesos & Php12.61 (SD \pm 6.84) & Php15.09 (SD \pm 8.26) \\
\hline
\end{tabular}

at the Family medicine clinic for a mean duration of 65 months $(\mathrm{SD} \pm 73.03)$ with the majority being symptomatic in the last 17 months $(\mathrm{SD} \pm 15.13)$. Diabetes mellitus was a comorbid condition among $43 \%(\mathrm{~N}=146)$ of participants while $75 \%(\mathrm{~N}=257)$ have hypertension. None of the respondents had depression and reported an average score of 16/25 $(\mathrm{SD} \pm 2.80)$ on the WHO sense of well-being index.

The current severity of pain showed a mean VAS score of 8.28 ( $\mathrm{SD} \pm 1.26)$ for both acute and chronic pain. Symptoms were present in 94\% acutely ill and 96\% chronically ill respondents who were drinking one pill per day. The use of topical analgesics was reported only by $15 \%$ of participants with chronic pain. Pills were usually purchased at a local drug store, while $3-5 \%$ availed of free medicines from the local health centers.

Current pain medications had an average anticipated time to take effect at 43.76 minutes $(\mathrm{SD} \pm 16.90)$ while painfree time was estimated at 14.24 hours $(\mathrm{SD} \pm$ 4.18). Pain scores had an average improvement of 5.44 points in VAS scores after intake of current medication resulting in a mean decrease of $54 \%$ in pain severity. Hence, because symptom relief is greater than $50 \%$, almost all $(93 \%, \mathrm{~N}=319)$ were satisfied with the existing pain medications.

\section{Preferences for Pain Medications}

Medications that decrease the worst musculoskeletal pain within 30 minutes after intake were preferred by $74 \%$ of patients with acute pain and $58 \%$ of patients with chronic symptoms. However, given equally effective drugs, but different price points, greater than half of the patients with acute or chronic pain will choose the lower price drug $(65 \%$ and 59\%). Also, patients with chronic and acute symptoms favor lower price medicine despite the slower onset of action when adverse events are less likely to occur (63\% and 70\%).

Drugs that can decrease pain by half at a $77 \%$ lower cost were preferred by $53 \%$ of patients with musculoskeletal pain compared to pain relief at $90 \%$ at a higher price point.
Similarly, $61 \%$ and $68 \%$ of the respondents with acute and chronic pain, respectively, prefer higher-priced pain medicine if it will improve a functional disability from severe to mild.

While majority of the respondents would choose a premium-priced pain relief medicine reported to be more effective and without adverse effect, there were also 109 patients (32\%) who would accept a chance of hepatic and renal risk for a more affordable drug. Lower priced medicine with slower onset of action and no adverse effects was also a preferred choice in $63 \%$ and $70 \%$ of patients with chronic and acute pain, respectively. The oral analgesic tablet was preferred by $59 \%$ of respondents with acute symptoms and $64 \%$ with chronic pain.

Overall, patients with musculoskeletal pain would prefer medicines at a lower price point which effectively reduces pain, with a fast onset of action, longer therapeutic effects, and fewer adverse effects. (Table 2)

\section{Cost of Current Pain Medications}

Adult Filipinos diagnosed with musculoskeletal disorders were spending an average of $\mathrm{Php} 13.12(\mathrm{SD} \pm 7.21$ ) per pill, regardless of pain chronicity. The highest price point for a medicine paid for acute musculoskeletal pain was Php 33.00, while a patient with chronic pain has paid up to Php 67.00 per pill.

Respondents with acute musculoskeletal pain were spending more for relief of acute pain at Php15.00/pill compared to adults with chronic symptoms at an average of Php12.60/pill.

\section{Willingness to Pay for Symptom Relief}

Overall, respondents were willing-to-pay an average of Php 86.11 (SD \pm 15.47$)$ per pill and therefore were willing to allocate $27 \%$ of the family monthly income for pain relief.

The willingness to pay for higher price medicine increased concurrently with the percent effectiveness of the 
Table 2. Medication Preference of Adult Filipinos with Acute and Chronic musculoskeletal pain seen and managed at the Family Medicine Clinic of Outpatient Department of Philippine General Hospital, September 2016- April 2017

\begin{tabular}{lcc}
\multicolumn{1}{c}{ Preferences for Medicines } & $\begin{array}{c}\text { Chronic Musculoskeletal } \\
\text { Pain (N=273) }\end{array}$ & $\begin{array}{c}\text { Acute Musculoskeletal } \\
\text { Pain (N=69) }\end{array}$ \\
$\begin{array}{ll}\text { A. Premium Price Medicines } \\
\text { 1. provides improvement of functional impairment to mild disability }\end{array}$ \\
$\begin{array}{l}\text { 2. effective with faster onset of action } \\
\text { 3. longer therapeutic effect }\end{array}$ & $61 \%(165)$ & $68 \%(47)$ \\
B. Lower Price Medicines & $49 \%(145)$ & $44 \%(30)$ \\
1. Onset of Action within 30 mins & $58 \%(40)$ \\
2. Onset of action within 60 mins & $58 \%(159)$ & $74 \%(51)$ \\
3. Medicine with no adverse effect but a slower onset of effect & $42 \%(114)$ & $26 \%(18)$ \\
C. Ease of administration & $63 \%(172)$ & $70 \%(48)$ \\
1. Prefers medicine taken orally than topically & $59 \%(161)$ & $59 \%(41)$ \\
2. Prefers medicine in tablet form & $59 \%(161)$ & $64 \%(44)$ \\
3. Prefers medicine needs to be taken less frequently even at premium price & $55 \%(149)$ & $67 \%(46)$ \\
\hline
\end{tabular}

Table 3. Willingness to Pay for pain relief of Adult Filipinos with Acute and Chronic musculoskeletal pain seen and managed at the Family Medicine Clinic of Outpatient Department of Philippine General Hospital, September 2016- April 2017

\begin{tabular}{|c|c|c|c|c|}
\hline Outcomes, Mean SD & $\begin{array}{c}\text { Chronic Musculoskeletal } \\
\text { Pain ( }=273)\end{array}$ & $\begin{array}{l}\text { Percentage decrease in } \\
\text { price of medicine patients } \\
\text { are willing to pay for* }\end{array}$ & $\begin{array}{l}\text { Acute Musculoskeletal } \\
\text { Pain (N=69) }\end{array}$ & $\begin{array}{l}\text { Percentage decrease in } \\
\text { price of medicine patients } \\
\text { are willing to pay for* }\end{array}$ \\
\hline \multicolumn{5}{|l|}{ a. Symptom Control } \\
\hline $\begin{array}{l}\text { Medicine that will give } \\
\text { complete symptom relief }\end{array}$ & Php 85.46 (SD \pm 14.72$)$ & reference & Php 88.68 (SD \pm 18.02$)$ & reference \\
\hline $\begin{array}{l}\text { Medicine that will decrease } \\
\text { symptoms by } 90 \% *\end{array}$ & Php 72.16 (SD \pm 17.60$)$ & $16 \%$ & Php 76.32 (SD \pm 19.03$)$ & $14 \%$ \\
\hline $\begin{array}{l}\text { Medicine that will decrease } \\
\text { symptoms by } 50 \%\end{array}$ & Php 48.85 (SD \pm 16.06$)$ & $43 \%$ & Php 51.71 (SD \pm 17.74$)$ & $42 \%$ \\
\hline $\begin{array}{l}\text { Medicine that will decrease } \\
\text { symptoms by } 30 \%\end{array}$ & Php 30.00 (SD \pm 17.15) & $65 \%$ & Php 32.43 (SD \pm 17.99$)$ & $63 \%$ \\
\hline \multicolumn{5}{|l|}{ b. Adverse Events } \\
\hline $\begin{array}{l}\text { Medicine that will have } \\
90 \% \text { less adverse event }\end{array}$ & Php $9.30(S D \pm 16.47)$ & reference & Php 9.87 (SD \pm 18.82) & reference \\
\hline $\begin{array}{l}\text { Medicine that will have } \\
50 \% \text { less adverse event** }\end{array}$ & Php 5.35 (SD \pm 13.85) & $42 \%$ & Php 7.58 (SD \pm 18.18$)$ & $23 \%$ \\
\hline
\end{tabular}

* computed using: reference complete symptom relief (Php85.46-72.16)/ 85.46*100;

${ }^{* *}$ computed using reference $90 \%$ less adverse events (Php9.30-5.35)/9.30*100

drug to alleviate pain. Acutely symptomatic respondents are willing to pay a few-peso higher than those with chronic pain symptoms. The average price of medication a patient was willing to pay for complete symptom relief of chronic and acute pain was $\mathrm{Php}$ 85.46 (SD \pm 14.72) and $\mathrm{Php} 88.68$ $(\mathrm{SD} \pm 18.02)$ per pill, respectively. For medicine that alleviates chronic pain by $30 \%$, there was a $65 \%$ decrease in the price of the medicine that patients were willing to pay. (Table 3) Similarly, the number of patients who were willing to pay for pain medicines decreased with increased frequency of adverse events. In general, patients presenting with acute and chronic pain were willing to pay higher price medicines for complete symptom relief and less adverse events. (Table 3)

\section{DISCUSSION}

The results of the study indicate that Filipino adults with acute and chronic musculoskeletal pain would prefer medicines at a lower price point but will effectively reduce pain, with a fast onset of action, longer therapeutic effects, and fewer adverse effects. However, there was a high willingness to pay for premium-priced medicines which can provide adequate pain management and minimize disability.

Factors influencing willingness to pay do not largely differ between respondents with acute and chronic pain. Patients with acute pain symptoms consider a premiumpriced medicine that provides improvement of functionality with a longer therapeutic effect. Respondents with chronic pain, on the other hand, prefer a premium-priced medicine that has a faster onset of action and is effective in reducing disability.

Efficacy and safety are the patient's primary considerations as symptom relief and fewer side effects have a higher level of willingness-to-pay among the respondents.

This is supported by a willingness to pay studies that had shown that reduction in pain intensity was valued equally as functional improvement and that pain is the most significant symptom that will drive willingness to pay 
among patients. Factors related to the reduction of pain showed that individuals do value improvements in painrelated disability and intensity. ${ }^{7}$ In fact, patients with pain due to osteoarthritis will pay a premium price on treatment that offers longer-lasting relief and improvement of physical functioning. ${ }^{8}$

Other factors affecting patient's willingness to pay pertaining to the attributes of musculoskeletal pain medication which include drug formulation, dosage preparation, route, frequency of use, and out-pocket cost. A similar study showed that each attribute was associated with price patients would pay to obtain the benefit of a drug that had these characteristics. ${ }^{9}$ Another study on patient preferences, drug characteristics generally contribute to treatment choice, adherence and eventual health status of patients. ${ }^{6}$

The respondents of the study were middle-aged, gainfully employed adults belonging to low socioeconomic income levels who were diagnosed with musculoskeletal pain for greater than six months. Most were able to choose the preferred drug in the task questions indicating that respondents correctly understood the questionnaires' content and therefore the data gathered were correct representations of patient's choices.

The preference and willingness to pay for a medicine that can provide complete symptom relief despite the high cost and relatively low financial capability can be due to the functional disability caused by musculoskeletal disorders affecting everyday daily activities and work. Daily income is important among socioeconomically disadvantaged patients who would prefer medications that can help reduce workrelated absences.

The trend for willingness to pay among patients also decreases if the reported effectiveness of the prescribed medication to provide symptom control was lowered. The greater than twenty percent change in price at complete symptom control to less effective medicine shows how patients place importance on adequate pain management despite the cost of drugs. Similarly, the average price patients are willing to pay decreases for medicine with more risk for adverse reactions. Differences in the price for which patients are willing to pay for symptom control and adverse effect demonstrate that respondents place more value on achieving complete relief of symptoms and improving pain-related disability despite potential side effects.

The impairment in functionality caused by musculoskeletal pain results in high health economic burden ${ }^{3}$ and this socio-economic impact emphasized the need for a more effective pain management plan. A big out-of-pocket expenditure for pain relievers implies that low-income earners incur high medical expenses, increasing the burden for the low-income group. Thus, most of the respondents preferred lower-priced medicine that will give the same effect of alleviating symptoms regardless of how fast the onset of action and adverse reactions.
The willingness to pay a substantial average amount of Php86.00 per pain reliever pill to provide a complete symptom control magnifies the socioeconomic burden particularly to the low-income group thus the need to look into the possibility of expanding healthcare coverage thru national health insurance scheme that would cater for the needs of patients with these kind of health conditions.

Other factors reported having significant associations with the willingness to pay among patients include age, educational attainment, income, household size, perception, health care services quality, locality rural/urban and ability to pay..$^{10}$ In contrast, the price of medicine was not found to influence WTP for health care.

Study limitations include non-description of the type of medication utilized by the respondents including branded or generic formulations and the degree of functional disability caused by acute or chronic musculoskeletal pain.

\section{CONCLUSION}

Adult Filipinos with musculoskeletal pain symptoms prefer pain medicines with good symptom control, less adverse event and were willing to pay for complete symptom relief at an average of eighty-six pesos per pill.

\section{Statement of Authorship}

Both authors participated in the data collection and analysis, and approved the final version submitted for publication.

\section{Author Disclosure}

There was no conflict of interest transpired during the conduct of this study.

Both authors declared that they have not received any payment or services from a third party for the submitted work.

\section{Funding Source}

The study was funded by the authors.

\section{REFERENCES}

1. Pongparadee C, Penserga E, Lee DJS, Chen S, Gill RS, Hamid A, et al. Current considerations for the management of musculoskeletal pain in Asian countries: a special focus on cyclooxygenase-2 inhibitors and non-steroid anti-inflammation drugs. Int J Rheum Dis. 2012 Aug; 15(4):341-7. doi:10.1111/j.1756-185X.2012.01769x.

2. 2. Lu H, Javier F. Prevalence and treatment of chronic pain in the Philippines. Philipp J Intern Med. 2011 Apr-Jun; 49(2):61-9.

3. Paananen M, Taimela S, Auvinen J, Tammelin T, Zitting P, Karppinen J. Impact of self-reported musculoskeletal pain on health-related quality of life among young adults. Pain Med. 2011 Jan; 12(1):9-17.

4. Bruyere $\mathrm{O}$, Reginster $\mathrm{J}$. The need for economic evaluation in osteoarthritis. Aging Health. 2009; 5(5):591-4.

5. Gerstner DG. Predictors of willingness to pay for health benefits: an exploratory analysis of willingness to pay for small to moderate health effects among musculoskeletal and psychosomatic patients undergoing rehabilitation in Germany [Internet]. Doctoral Dissertation. 2011 [cited 2017 Aug 12]. Available from: https://www.deutschedigitalebibliothek.de/ 
6. Kleinman L, McIntosh E, Ryan M, Schmier J, Crawley J, Locke GR,et al. Willingness to pay for complete symptom relief of gastroesophageal reflux disease. Arch Intern Med. 2002 Jun; 162(12):1361-6. doi: 10.1001/archinte.162.12.1361.

7. Chuck A, Adamowicz W, Jacobs P, Ohinmaa A, Dick B, Rashiq S. The willingness to pay for reducing pain and pain-related disability. Value Health. 2009 Jun; 12(4):498-506. doi: 111/j.154-4733.2008.00457.x.

8. Posnett J, Dixit S, Oppenheimer B, Kili S, Mehin N. Patient preference and willingness to pay for knee osteoarthritis treatments. Patient Prefer Adherence. 2015 Jun; 9:733-44. doi:10.2147/PPA.S84251.
9. Kawata AK, Kleinman L, Harding G, Ramachandran S. Evaluation of patient preference and willingness to pay for attributes of maintenance medication for chronic obstructive pulmonary disease. Patient. 2014; 7(4):413-26. doi: 10.1007/s40271-014-0064-1.

10. Aizuddin AN, Sulong S, Aljunid SM. Factors influencing willingness to pay for healthcare. BMC Public Health. 2012 Nov; 12:A37.

The Acta Medica Philippina is now accepting original scientific papers, review articles and case reports for its upcoming issues. Please follow the format for submission as indicated in the "Instructions to Authors" elsewhere in the journal. All papers received shall be properly acknowledged. For inquiries and submission of proposals, please email us at actamedicaphilippina.upm@up.edu.ph 